\title{
Mechanisms of the Reverse Martensite-to-Austenite Transformation in a Metastable Austenitic Stainless Steel
}

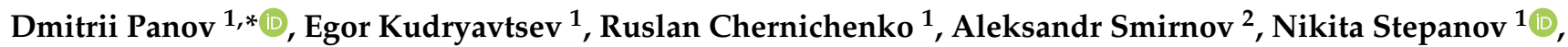 \\ Yuri Simonov ${ }^{3}$, Sergey Zherebtsov ${ }^{1}\left[\right.$ and Gennady Salishchev ${ }^{1}$ (i)
}

1 Laboratory of Bulk Nanostructured Materials, Belgorod State University, 85 Pobeda Str., 308015 Belgorod, Russia; kudryavtsev@bsu.edu.ru (E.K.); chernichenko@bsu.edu.ru (R.C.); stepanov@bsu.edu.ru (N.S.); Zherebtsov@bsu.edu.ru (S.Z.); salishchev@bsu.edu.ru (G.S.)

2 Department of Materials Science in Engineering, Novosibirsk State Technical University, 20 Prospekt K. Marksa, 630073 Novosibirsk, Russia; a_smirnov@ngs.ru

3 Department of Metal Science, Thermal and Laser Processing of Metals, Perm National Research Polytechnic University, 29 Komsomolsky Prospekt, 614990 Perm, Russia; simonov@pstu.ru

* Correspondence: Panov_D@bsu.edu.ru

check for updates

Citation: Panov, D.; Kudryavtsev, E.; Chernichenko, R.; Smirnov, A.; Stepanov, N.; Simonov, Y.; Zherebtsov, S.; Salishchev, G. Mechanisms of the Reverse Martensite-to-Austenite Transformation in a Metastable Austenitic Stainless Steel. Metals 2021, 11, 599. https://doi.org/10.3390/ met11040599

Academic Editor: Paolo Matteis

Received: 15 March 2021

Accepted: 3 April 2021

Published: 6 April 2021

Publisher's Note: MDPI stays neutral with regard to jurisdictional claims in published maps and institutional affiliations.

Copyright: (c) 2021 by the authors. Licensee MDPI, Basel, Switzerland. This article is an open access article distributed under the terms and conditions of the Creative Commons Attribution (CC BY) license (https:// creativecommons.org/licenses/by/ $4.0 /)$.

\begin{abstract}
The martensite-to-austenite reversion mechanisms under continuous heating and annealing of metastable austenitic stainless steel subjected to cold swaging were studied. The reversiontemperature-time diagram was constructed using high-resolution dilatometry. The diagram revealed a sequence of martensitic and diffusional reversion and recrystallization. Martensitic and diffusional reversion might be separated by using the heating rate of $>10{ }^{\circ} \mathrm{C} / \mathrm{s}$. The reversion started via the martensitic mechanism, and the diffusional mechanism developed during subsequent heating. However, both mechanisms enhance simultaneously during continuous heating at slow heating rates $\left(<10^{\circ} \mathrm{C} / \mathrm{s}\right)$. At higher temperatures, recrystallization occurred. Post-mortem microstructure analysis has allowed classifying the reverse annealing modes into low- $\left(500-650{ }^{\circ} \mathrm{C}\right)$, medium- $\left(700{ }^{\circ} \mathrm{C}\right)$, and high-temperature $\left(\sim 800^{\circ} \mathrm{C}\right)$ regimes. During low-temperature annealing, the development of the phase reversion, recovery, recrystallization, and carbide precipitation was characterized by both a high amount of new austenite grains and restriction of their growth that resulted in the formation of an ultrafine grain structure with an average grain size of 100-200 nm. Medium-temperature annealing was associated with the formation of almost a fully recrystallized austenitic structure, but the lamellar regions were still detected. Austenitic grain growth and dissolution of carbide particles were enhanced during high-temperature annealing.
\end{abstract}

Keywords: metastable austenitic stainless steel; dilatometry; reversion; deformation-induced martensite; reverted austenite; recrystallization

\section{Introduction}

Metastable austenitic stainless (MAS) steels have a very attractive combination of properties such as high ductility and impact toughness, excellent corrosion and oxidation resistance, good weldability, and superior formability [1,2]. However, they exhibit low yield strength that inhibits their application as a structural material. Increasing the yield strength by the grain size refinement is considered to be the most promising pathway to solve the problem [3,4]. It is possible to refine a MAS steel structure by severe plastic deformation (SPD) at room temperature and below, using such technics as equal channel angular pressing, rolling, high-pressure torsion, multiaxial forging, and swaging [5-10]. Besides mechanical twinning, substructure, and deformation band formation, deformationinduced $\gamma \rightarrow \alpha^{\prime}$ transformation occurs during SPD [11-14]. It was reported [13,14] that austenite with face-centered cubic (FCC) lattice and deformation-induced martensite (DIM) with body-centered tetragonal (BCT) lattice are related through the Kurdjumov-Sachs (K-S) orientation relationship that is $\{111\}_{\gamma} \|\{110\}_{\alpha \prime}$ and $\langle 110\rangle_{\gamma} \|\langle 111\rangle_{\alpha \prime}$. However, a decrease 
in the characteristics of ductility and toughness is often observed after SPD processing that is caused by low strain hardening ability and soon strain localization upon loading $[15,16]$.

Phase reversion annealing after SPD may result in favorable strength-ductility synergy for materials [17-19] due to the formation of a heterogeneous austenite structure. In such a structure, grains are believed to possess different stability under loading that is associated with multi-stage transformation-induced plasticity (TRIP) and improved strain-hardening ability. The processing leads to the development of the reversion of DIM to austenite that may occur via martensitic or diffusional mechanisms [20-22]. The activation of a particular mechanism depends on the chemical composition [22], stored deformation energy [23], heating rate [24], soaking time, and annealing temperature [25,26]; both martensitic and diffusional mechanisms might occur simultaneously [12]. In the case of the diffusional mechanism, the reverse transformation start temperature $\left(\mathrm{A}_{S}\right)$ rises with increasing the heating rate but changing to martensitic mechanism is associated with stabilization of the $A_{S}$ level [24]. During the martensitic reversion, the K-S orientation relationship between DIM and reverted austenite is detected and accompanied by the "memory" effect [21,22,27]. The latest is associated with inhering the crystallographic orientation of a former austenite grain due to apparent variant selection $[28,29]$. However, the diffusional reversion does not allow maintaining a specific orientation relationship between reversed austenite and initial DIM [22]. Furthermore, static recrystallization develops after the phase reversion at high temperatures [30].

Up to date, it should be mentioned that some reversion-temperature-time diagrams have been suggested which clearly describe dynamic the reverse transformation start and finish temperatures [24,31] and schematically estimate the position of different transformation fields [20]. Permitting to analyze heating processes "in situ" and separate effects from various transformations, modern approaches in high-resolution dilatometry [32-34] have not still applied for a study of martensite-to-austenite reversion. Furthermore, the effect of heating rate on competition martensitic and diffusional mechanisms has not been studied completely. Moreover, there is not a common viewpoint about the sequence of those mechanisms in MAS steels. According to [25], the martensitic shear reversion takes place at lower temperatures that are associated with the formation of reverted austenite (RA) with high crystal defect concentration inside and the K-S orientation relationship between RA and DIM. The formation of defect-free grains occurs at higher temperatures that indicate the reversion by the diffusional mechanism. In contrast, due to the higher driving force, the diffusional reversion is believed to be at lower temperatures, but, at higher temperatures, the martensitic mechanism of reversion might be activated when the driving force reaches the appropriate value [35]. Thus, the present study aimed to discover the mechanisms and effect of phase reverse annealing on the structure of metastable austenitic stainless steel subjected to severe cold swaging.

\section{Materials and Methods}

\subsection{As-Received and As-Processed Condition}

The program material used in the current study was a commercial type 321 steel. The chemical composition of the program material was presented in Table 1. To obtain the fully austenitic structure with an average grain size of $10 \mu \mathrm{m}$ (as-received condition) the initial hot-forged bar with a diameter of $33 \mathrm{~mm}$ was annealed at $1050^{\circ} \mathrm{C}$ for $1 \mathrm{~h}$ followed by water quenching. A few large irregular-shaped primary titanium carbonitrides and grains of $\delta$-ferrite oriented along the rod axis were detected in the structure [10]. The content of $\delta$-ferrite did not exceed $2 \%$. Then, the bar was subjected to cold swaging at room temperature using a radial forging machine SXP-16 with four radially moving hammers with the following mode: workpiece feeding rate $180 \mathrm{~mm} / \mathrm{min}$, stroke frequency 1000 blows per minute, workpiece rotation speed $25 \mathrm{rpm}$. Swaging was performed in five steps: deformation from $\varnothing 33$ to $\varnothing 29 \mathrm{~mm}$, from $\varnothing 29$ to $\varnothing 25 \mathrm{~mm}$, from $\varnothing 25$ to $\varnothing 20 \mathrm{~mm}$, from $\varnothing 20$ to ø $14 \mathrm{~mm}$ and from ø 14 to ø $11.3 \mathrm{~mm}$, which corresponded to $\sim 20 \%, \sim 40 \%, \sim 60 \%$, 
$\sim 80 \%$ and $\sim 90 \%$ of strain, respectively. The true strain corresponding to the final step of forging (as-processed condition) was 2.14.

Table 1. Chemical composition of the program material.

\begin{tabular}{cccccccccc}
\hline Chemical Elements & $\mathbf{C}$ & $\mathbf{C r}$ & $\mathbf{N i}$ & $\mathbf{M n}$ & $\mathbf{S i}$ & $\mathbf{T i}$ & $\mathbf{P}$ & $\mathbf{S}$ & $\mathbf{F e}$ \\
\hline Concentration (\% wt.) & 0.07 & 18.75 & 9.20 & 1.12 & 0.39 & 0.59 & 0.019 & 0.005 & basis \\
\hline
\end{tabular}

\subsection{Continuous Heating and Phase Reversion Annealing of the As-Processed Program Steel}

Continuous heating to $1000{ }^{\circ} \mathrm{C}$ was performed using a Linseis R.I.T.A. L78 quenching dilatometer in helium (99.9999\%) atmosphere at heating rates of 400,90, 10, 0.6, and $0.15^{\circ} \mathrm{C} / \mathrm{s}$. Cylindrical samples were cut along the axis of the as-processed rod from its center and had a diameter of $3 \mathrm{~mm}$ and a height of $10 \mathrm{~mm}$. During continuous heating, the temperature of the sample was measured by a type $\mathrm{K}$ thermocouple that was welded at the center of a generating line using electric resistant welding. Subsequent analysis of dilatograms was conducted using the Fityk software (v. 0.9.8) [36]. Asymmetric Gaussian curves were used for the approximation of the obtaining results. The corresponding R-square values were $0.90-0.99$.

Phase reverse annealing was carried out using a furnace at temperatures of 400, 500, $550,600,650,700,800,900{ }^{\circ} \mathrm{C}$ with a soaking time of $2 \mathrm{~h}$ in a furnace and subsequent air-cooling to room temperature.

\subsection{Structure and Hardness Characterization}

The microstructure of the program steel was examined by transmission electron microscopy (TEM). TEM was performed using a JEOL JEM-2100 electron microscope with an accelerating voltage of $200 \mathrm{kV}$. Flat templets with a thickness of $0.3 \mathrm{~mm}$ were cut in the cross and longitudinal axial section from the bar by a Sodick AQ300L wire electrical discharge machine. Then, the templets were performed double-sided thinning to $0.1 \mathrm{~mm}$ thickness. Subsequent conventional twinjet electro-polishing of discs with $3 \mathrm{~mm}$ diameter was carried out using TenuPol-5. The electrolyte consisted of 5\% perchloric acid, 35\% butanol, and $60 \%$ methanol. The voltage and temperature of the polishing were $27 \mathrm{~V}$ and $-40{ }^{\circ} \mathrm{C}$, respectively. The microstructural parameters were determined using the Olympus Stream Motion software (v. 1.8) on bright- and dark-field TEM images. Then, the results were statistically analyzed via averaging and calculation of the confidence interval with the significance level of $5 \%$.

X-ray diffraction analysis (XRD) was carried out using a Rigaku Ultima IV diffractometer and $\mathrm{CuK} \alpha$ radiation. Scanning was conducted using the standard Bragg-Brentano geometry in the $2 \theta$ interval of $40-100^{\circ}$ with a step of $0.02^{\circ}$.

The Vickers microhardness testing was carried out by a IT 5010 hardness tester equipped with a diamond pyramid indenter with a base angle of $136^{\circ}$. The measurements were performed at the central part of the cross-section. The loading and soaking times were $50 \mathrm{~g}$ and $10 \mathrm{~s}$, respectively.

The content of the magnetic $\alpha$-phase was also determined at the central part of the cross-section using a FERRITSCOPE FMP30 eddy-current tester with the converter detector FGAB1.3-Fe. Ten measurements were made and averaged. Then the calculation of the confidence interval with the significance level of $5 \%$ was performed.

\section{Results and Discussion}

\subsection{As-Received and As-Processed Microstructure}

The structure evolution during cold swaging of the as-received program steel was studied in details in the previous work [10]. Therefore, only brief information is shown here. The effect of strain on the $\alpha$-phase content $\left(\mathrm{V}_{\alpha}, \%\right)$ and hardness is presented in Figure 1a. Obtaining by eddy-current testing, the $\alpha$-phase content $\left(\mathrm{V}_{\alpha}, \%\right)$ included $\delta$-ferrite $(\sim 2 \%)$, which was inherited from the as-received condition, and deformation- 
induced $\alpha^{\prime}$-martensite (DIM). Cold swaging resulted in a continuous increase in the $\alpha$ phase volume fraction to $10 \%$ after $40 \%$ reduction and to $38 \%$ after $90 \%$ reduction. The changes in the intensity of peaks corresponding to $\alpha$ and $\gamma$ phases were also detected on the XRD pattern (Figure 1b). Specifically, the intensity of the (110) $\alpha$ peak distinctly increased after cold swaging. On the other hand, the (200) $\gamma$ peak significantly decreased, but the (220) $\gamma$ and (311) $\gamma$ reflections completely disappeared. Simultaneously, hardness increased from 203 to $450 \mathrm{HV}$ with increasing strain from 0 to $90 \%$, respectively.
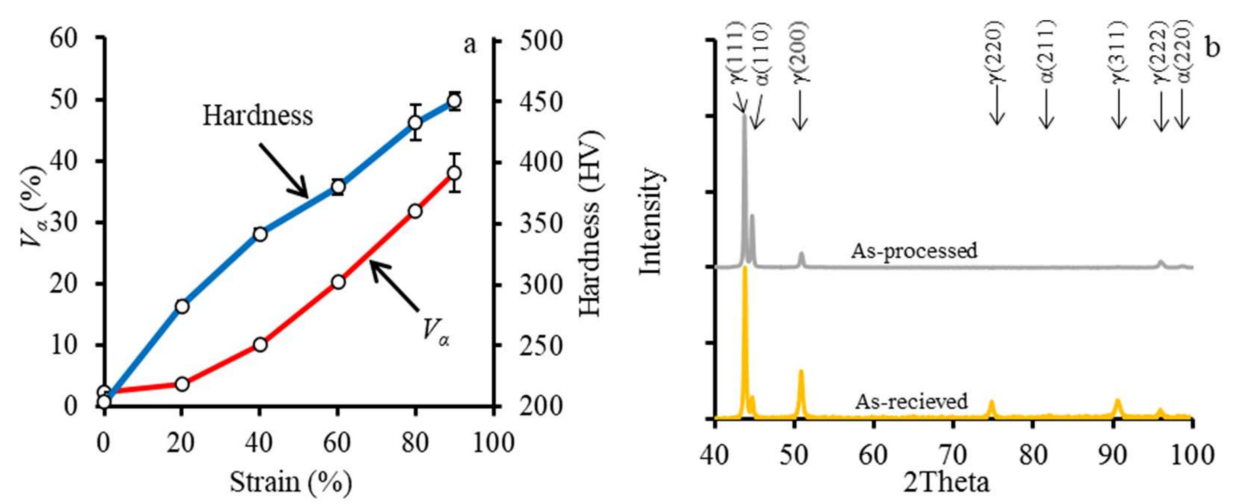

Figure 1. (a) Effect of cold strain on the $\alpha$-phase content $\left(\mathrm{V}_{\alpha}\right)$ and hardness and (b) XRD patterns of the as-received and as-processed program steel.

TEM micrographs of the as-received and as-processed structure are presented in Figure 2. The as-received structure consisted of austenite grains with annealing twins and a few uniformly distributed dislocations inside (Figure 2a). In the transversal section of the bar in the as-processed state, regions of austenite (Figure $2 \mathrm{~b}$ and c) and DIM (Figure 2d) possessed lamellar packet-like and nearly equiaxed shape. The transition from lamellar to the equiaxed structure occurred at the latter stage (at the strain above $60 \%$ ) of cold swaging [10,37], but the transformation was not complete at the strain of $90 \%$ (Figure 2e). Additional lattice defects introduced in the DIM-containing alloy during cold deformation caused the transformation [26]. In the longitudinal section, the lamellar structure comprised of austenite and martensite laths was observed (Figure 2f). The lamellae were oriented along the bar axis; transversal dislocation boundaries were found inside. It should be noted that twins were not detected because of the restriction effect $[38,39]$.

\subsection{High-Resolution Dilatometry during Continuous Heating}

The results of dilatometric measurements at a heating rate of $400{ }^{\circ} \mathrm{C} / \mathrm{s}$ for the asreceived and as-processed program steel are shown in Figure 3. Heating dilatometric data for other heating rates $\left(90,10,0.6\right.$, and $\left.0.15^{\circ} \mathrm{C} / \mathrm{s}\right)$ are presented in Supplementary Materials. For the as-received program steel, the inflections of the dilatogram ( $\Delta \mathrm{l}$-curve) were not detected. The first derivative of the dilatogram $(\mathrm{d}(\Delta \mathrm{l}) / \mathrm{dt}$-curve) also did not indicate any phase transformations (Figure 3a). The thermal effect, which might be estimated as a sharp inflection of difference $(\Delta t)$ between the set value of temperature (Set value) and real temperature of a specimen $(t)$, was also absent (Figure $3 b$ ).

Meanwhile, the dilatogram of the as-processed program steel demonstrated the sequence of inflections that could be likely associated with the martensite-to-austenite reversion (Figure 3c). Indeed, the well-defined thermal effect, associated with the martensite-toaustenite reversion, was detected (Figure $3 \mathrm{~d})$. Hence, the reverse transformation start temperature $\left(\mathrm{A}_{S}\right)$ was measured both by dilatometric $\left(\sim 524^{\circ} \mathrm{C}\right)$ and thermal effects $\left(\sim 526^{\circ} \mathrm{C}\right)$. The $\mathrm{d}(\Delta \mathrm{l}) / \mathrm{dt}$-curve showed sharp inflection from the linear part, thereby $\mathrm{A}_{\mathrm{S}}$ might be estimated as a launch point of the tangent line (Figure 3c). A similar analysis can be performed for the thermal effect (Figure 3d). The average measured $A_{S}$ value was $525^{\circ} \mathrm{C}$. The finish reversion temperature $\left(\mathrm{A}_{\mathrm{F}}\right)$ was estimated by a launch point of the tangent line to a linear part of the curve after the detected inflections using the dilatometric effect (Figure 3c). 

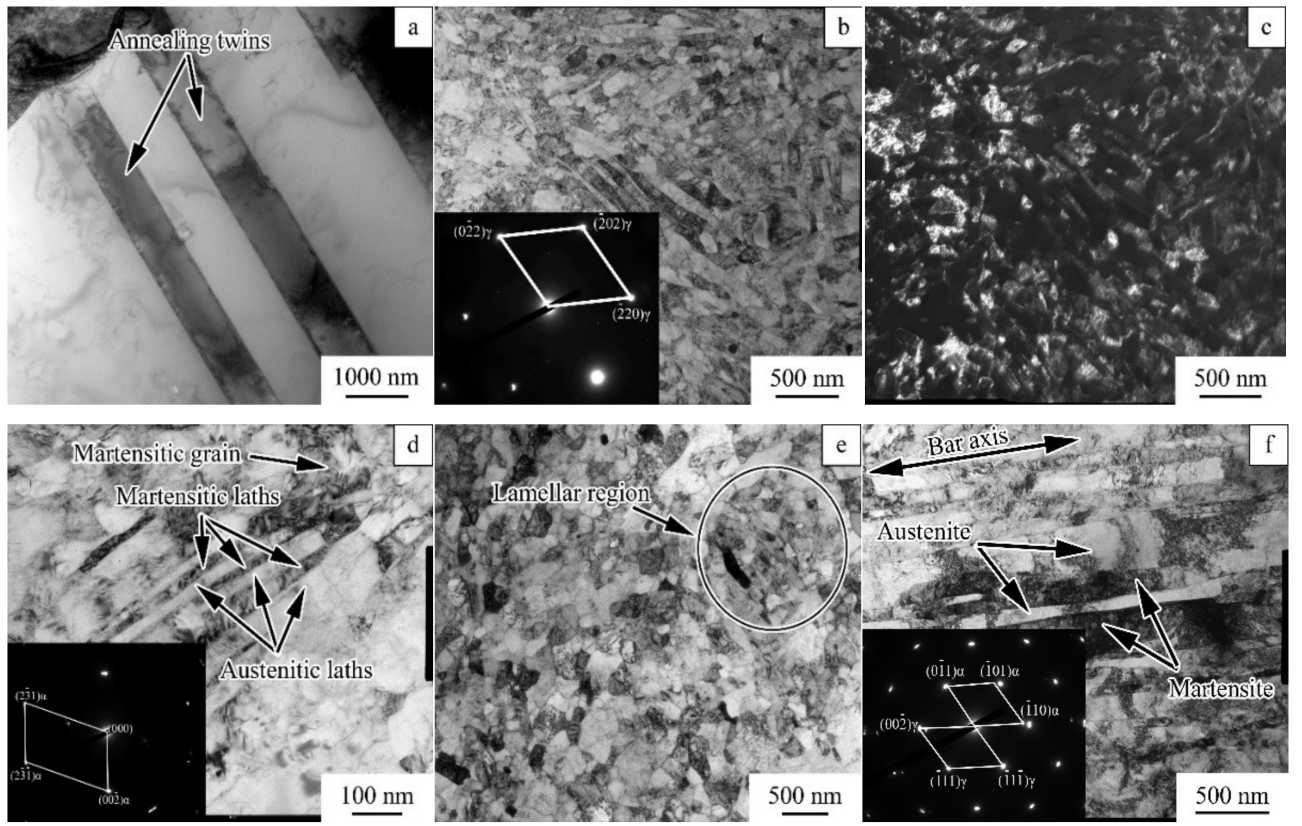

Figure 2. TEM micrographs of the program steel in the (a-e) transversal and (f) longitudinal sections the (a) as-received and $(\mathbf{b}-\mathbf{f})$ as-processed state: $(\mathbf{a}, \mathbf{b}, \mathbf{d}-\mathbf{f})$ - bright-field images; (c) —-dark-field images from $(\mathbf{b})$ at the $(\overline{2} 02)_{\gamma}$ reflection.
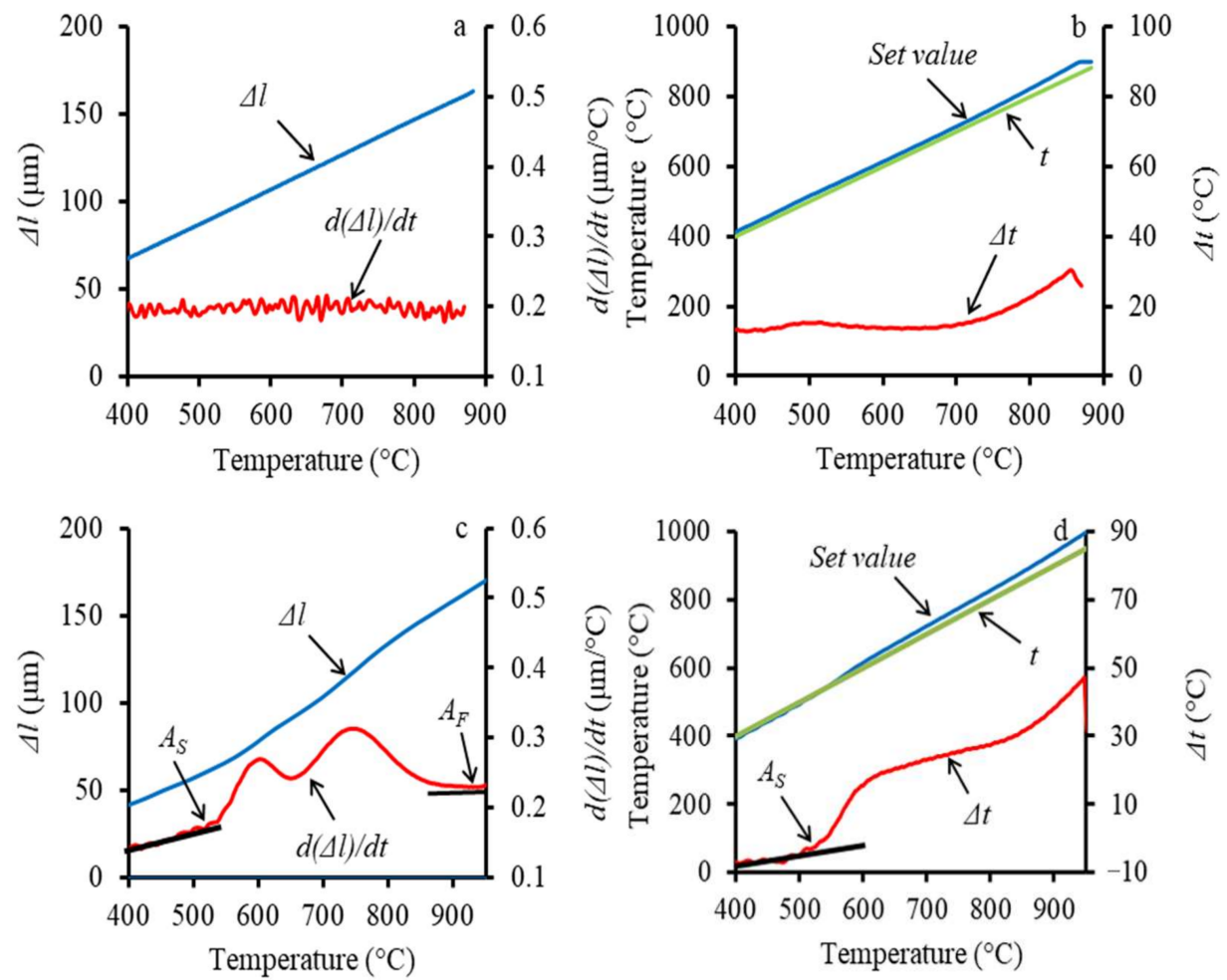

Figure 3. The results of dilatometric measurements at a heating rate of $400{ }^{\circ} \mathrm{C} / \mathrm{s}$ of the as-received $(\mathbf{a}, \mathbf{b})$ and as-processed program steel $(\mathbf{c}, \mathbf{d}):(\mathbf{a}, \mathbf{c})$ - dilatogram $(\Delta \mathrm{l})$ and the first derivative $(\mathrm{d}(\Delta \mathrm{l}) / \mathrm{dt})$; $(\mathbf{b}, \mathbf{d})$ - set value of temperature (Set value), the real temperature of a specimen $(t)$, the difference between the set value of temperature and real temperature of a specimen $(\Delta t)$.

Within the temperature range of the martensite-to-austenite reversion, the shape of the $\mathrm{d}(\Delta \mathrm{l}) / \mathrm{dt}$-curve was evidentially produced by the superposition of several peaks, 
presumably from the different processes (Figure 3c). The onset and end of each peak on the $\mathrm{d}(\Delta \mathrm{l}) / \mathrm{dt}$-curve corresponded to the temperatures of the start and finish of the process, respectively; the peak area was related to the volume effect of the transformation [40]; and the maximum was associated with the highest rate of the process. Further, a fitting procedure was used to separate these peaks from each other [34]. The analysis of the $\mathrm{d}(\Delta \mathrm{l}) / \mathrm{dt}$-curves revealed three distinctive peaks in the $\mathrm{A}_{\mathrm{S}}-\mathrm{A}_{\mathrm{F}}$ range at all studied heating rates; an example obtained at $400{ }^{\circ} \mathrm{C} / \mathrm{s}$ is shown in Figure 4 a. The first and second peaks were oriented upward from the baseline and therefore were associated with an increase in the length of the sample. These peaks were apparently direct effects of the different stages of the reversion. According to [41], a similar anomalous linear expansion during the martensite-to-austenite reversion was detected in the AISI 304 steel due to the effect of the gamma fiber texture $(\{111\}<110>$ and $\{111\}<112>)$ in DIM. The downward orientation of peak \#3 from the baseline detected decreasing the sample length (Figure 4a). According to [42], the resemble effect in the cold-deformed program steel earlier corresponded to the development of recrystallization during continuous heating. It should be noted that all three peaks under consideration were detected at all applied heating rates.
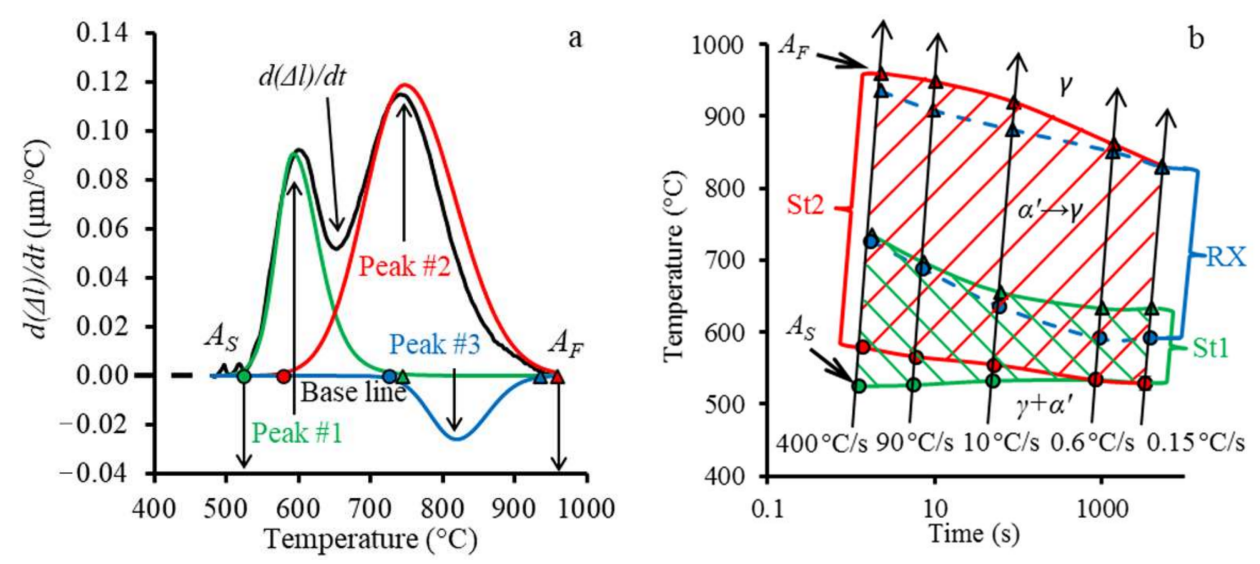

Figure 4. (a) The scheme of fitting the $\mathrm{d}(\Delta \mathrm{l}) / \mathrm{dt}$-curve and (b) the reversion-temperature-time diagram for the as-processed program steel. Notation: St1—first reversion stage; St2—second reversion stage; $\mathrm{RX}$-recrystallization.

After analysis of all heating dilatograms obtaining with various heating rates, the reversion-temperature-time diagram for the as-processed program steel was constructed (Figure $4 \mathrm{~b}$ ). Interestingly, the reverse transformation start temperature ( $\mathrm{A}_{\mathrm{S}}$ ) was $\sim 530{ }^{\circ} \mathrm{C}$ and did not depend on the heating rate. So, the start of the first reversion stage (St1) also did not depend on the heating rate, but the finish of it increased with the rising of the heating rate as well as the start and finish of the second reversion stage (St2) and the temperature range of recrystallization ( $\mathrm{RX})$. A significant influence of the heating rate on reversion mechanisms was reported earlier in Refs. [24,43]. So, at a heating rate less than $10^{\circ} \mathrm{C} / \mathrm{s}$, the diffusional mechanism of the reversion was developed. Yet the martensitic mechanism occurs at rapid heating with a rate of more than $40^{\circ} \mathrm{C} / \mathrm{s}$. In the current study, the heating with a rate higher than $\sim 10^{\circ} \mathrm{C} / \mathrm{s}$ was associated with the development of both reversion mechanisms separately. According to [20,24], the start and finish temperature of the diffusional reversion dramatically depended on the heating rate, yet the ones of martensitic shear reversion were irrespective of it. Thus, the first reversion stage (St1) could be associated with the martensitic mechanism that developed in all ranges of heating rates under study. Meanwhile, the second reversion stage (St2) was characterized by the diffusional mechanism due to the sensitivity of its temperature range to the heating rate. Thus, the approach suggested in the present work for analysis of the results of dilatometric measurements permitted to reveal the temperature range of the different reversion stages and construct a new reversion-temperature-time diagram for the commercial type 321 steel. 


\subsection{Microstructural Evolution during Annealing}

The dependence of the $\alpha$-phase content and hardness on the annealing temperature and the respective XRD patterns of the as-processed steel are presented in Figure 5. Annealing at $400{ }^{\circ} \mathrm{C}$ has not resulted in noticeable changes in the volume fraction of $\alpha$-phase, but hardness increased from $450 \mathrm{HV}$ to $488 \mathrm{HV}$. On the one hand, it can be associated with suppressing dislocation motion, caused by redistribution of carbon in solid solution due to thermal activation. On the other hand, the equilibrium phase diagram constructed by ThermoCalc predicted the precipitation of $\mathrm{CrC}$ and $\mathrm{Ni}_{3}$ Ti particles at $400{ }^{\circ} \mathrm{C}$, which might also result in strengthening [25]. Yet any such particles were not found in the current study. With increasing annealing temperature to $500{ }^{\circ} \mathrm{C}$, hardness remained at the same level, though the $\alpha$-phase content decreased from $38 \%$ to $34 \%$. It is well-known that the hardness of DIM is somewhat lower than the hardness of surrounding austenite [44], so slight decreasing the DIM volume fraction might be compensated by the possible structure refinement. The latter can be associated with the start of the martensite-to-austenite reversion. The subsequent increasing annealing temperature to $700{ }^{\circ} \mathrm{C}$ led to a significant decrease in both $\alpha$-phase content and hardness to 3\% and $279 \mathrm{HV}$, respectively. Further increase in annealing temperature to $900{ }^{\circ} \mathrm{C}$ was associated with decreasing the hardness value to $201 \mathrm{HV}$. The obtained hardness value was close to the hardness of the as-received condition (Figure 1a), possibly, due to grain coarsening during soaking at elevated temperatures.
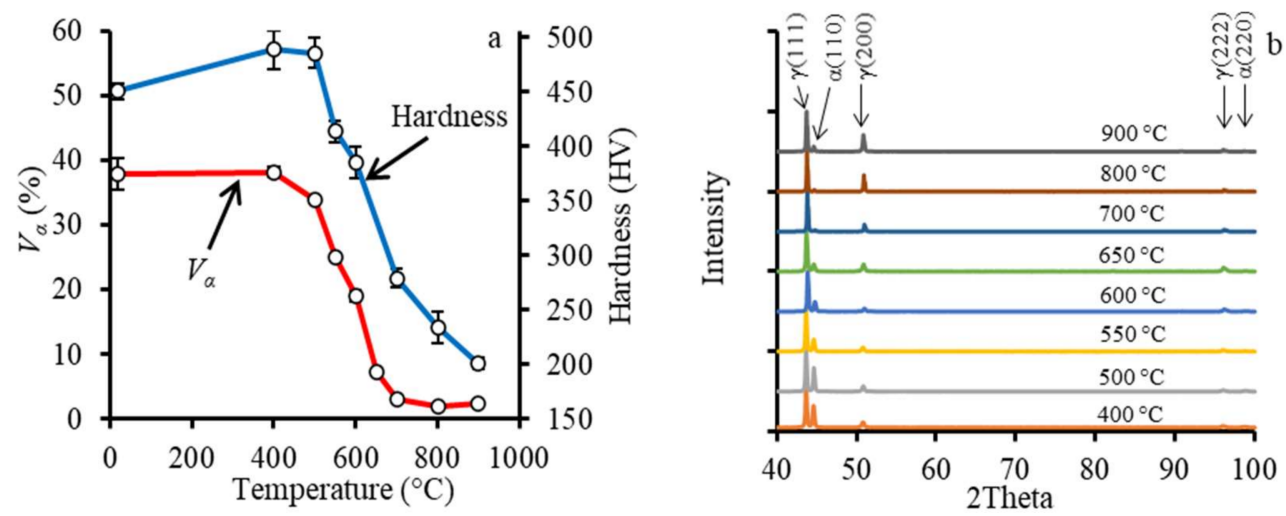

Figure 5. (a) Effect of annealing temperature on the $\alpha$-phase content $\left(\mathrm{V}_{\alpha}, \%\right)$ and hardness (b) XRD patterns of the as-processed program steel after annealing.

The XRD patterns revealed a gradual decrease in intensity of the DIM $(\alpha)$ peaks with increasing annealing temperature from 500 to $700{ }^{\circ} \mathrm{C}$ (Figure 5b). Further increase in annealing temperature resulted in noticeable changes in the DIM peaks intensity possibly due to the completion of the reversion at lower temperatures. Meanwhile, the intensity of the (200) $\gamma$ reflection increased significantly in the temperature range of $700-900^{\circ} \mathrm{C}$. This finding can be associated with recovery and recrystallization of reverted and retained austenite.

The TEM-structures of the program steel after annealing at different temperatures are presented in Figure 6 andFigure 7. After annealing at 500-650 ${ }^{\circ} \mathrm{C}$, microstructural observations have revealed several processes: formation of dislocations walls within both martensitic and austenitic lamellae (Figure 6a); lath-to-lath reversion within lamellar regions (Figure $6 \mathrm{~b}, \mathrm{c}$ ); the nucleation of the dislocation-free austenitic grains (Figure $6 \mathrm{~d}$ ); the formation of austenite plates and equiaxed austenite grains within the equiaxed $\alpha^{\prime}$-grains (Figure 6e); precipitation of chromium carbide particles $\left(\mathrm{Cr}_{23} \mathrm{C}_{6}\right)$ (Figure $6 \mathrm{f}$ ). Carbides evidentially pinned the recrystallized grains growth.

Microstructural observations confirm that both martensitic and diffusional mechanisms of the reversion were active during annealing at $500-650{ }^{\circ} \mathrm{C}$. On the one hand, austenite plates with several dislocations inside (Figure 6e), forming in the equiaxed $\alpha^{\prime}$-grains from the boundary into the grain body, were produced via the martensitic mechanism [26,45]. On the other hand, equiaxed dislocation-free austenite grains at the 
boundaries of $\alpha^{\prime}$-grains (Figure 6e) with the curved boundaries were the products of the diffusional mechanism [46]. Simultaneous occurrence of both martensitic and diffusional mechanisms also was reported earlier for cold-rolled AISI 304 steel [12]. Within lamellar regions, the reversion mostly occurred via the martensitic mechanism that resulted in preserving the lamellar structure (Figure $6 \mathrm{~b}, \mathrm{c}$ ). However, a few austenitic grains within some packets (Figure $6 \mathrm{~b}$ ) might be associated with the activation of the diffusional mechanism. Annealing at $700{ }^{\circ} \mathrm{C}$ was characterized by almost complete phase reversion (Figure 5a) and recrystallization of former fragmented regions (Figure 7a), but lamellar austenitic regions were still observed (Figure $7 \mathrm{~b}$ ). At $800^{\circ} \mathrm{C}$, austenitic grain growth was enhanced, possibly due to intensive dissolution of carbide particles were enhanced (Figure 7c).

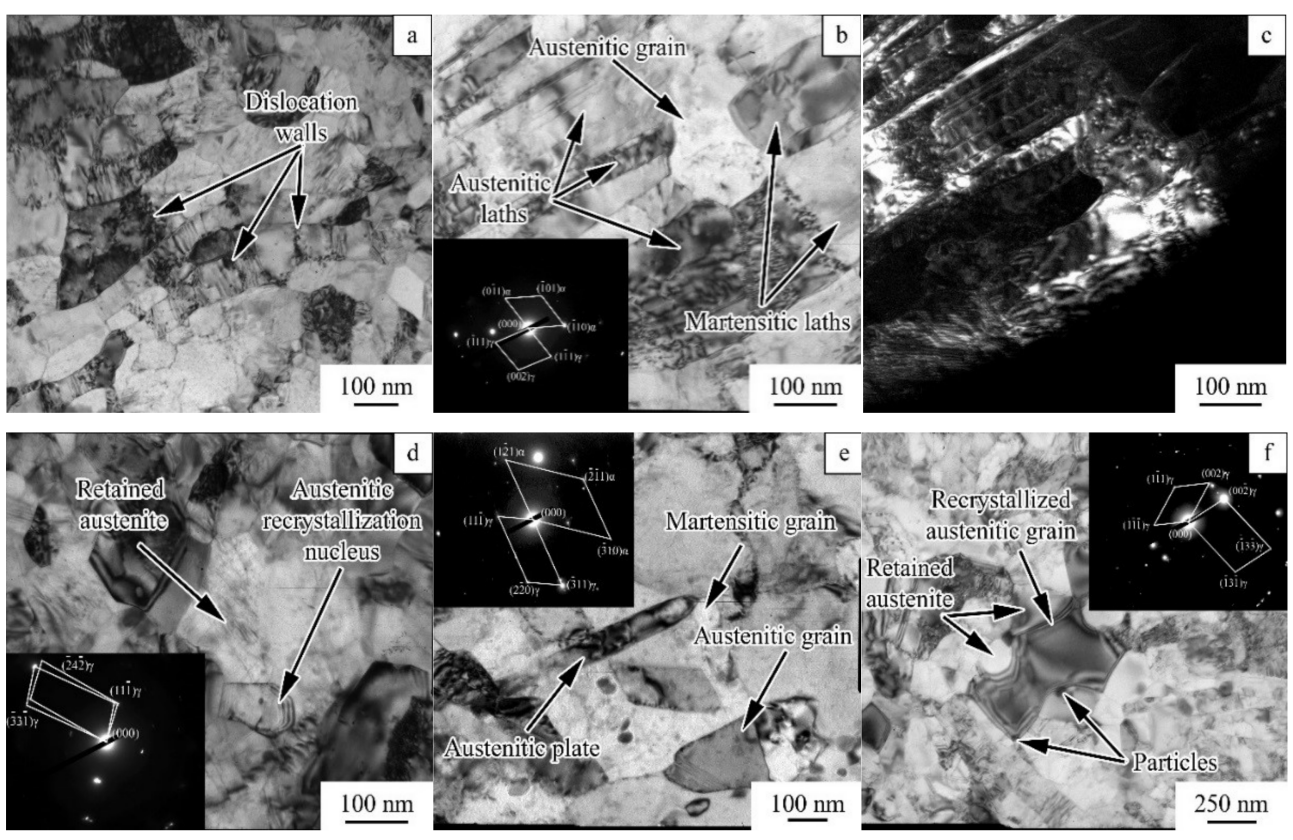

Figure 6. TEM micrographs in the transversal section after annealing at (a) 500, (b-d) 550, (e) 600, and (f) $650^{\circ} \mathrm{C}:(\mathbf{a}, \mathbf{b}, \mathbf{d}-\mathbf{f})$ - bright-field images; (c) —dark-field image from (b) at the $(1 \overline{1} 1)_{\gamma}$ reflection.

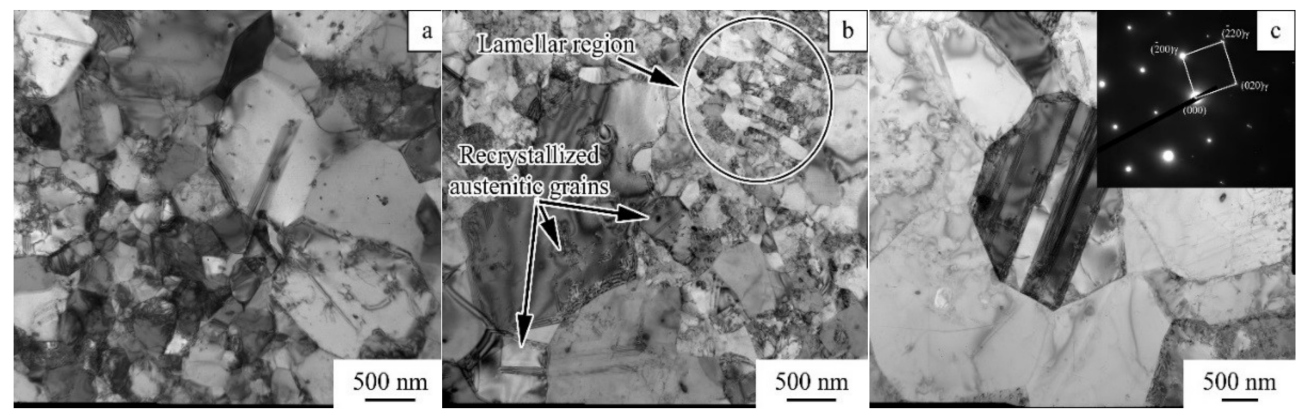

Figure 7. TEM micrographs in the transversal section after annealing at (a,b) 700 and (c) $800{ }^{\circ} \mathrm{C}$.

The effect of annealing temperature on the transversal grain/subgrain size and dislocation density is shown in Figure 8. After annealing at $500{ }^{\circ} \mathrm{C}$, the grain size decreased in comparison with the as-processed condition. Grain refinement was probably associated with the fragmentation of lamellae by dislocation walls and new austenitic grains formation via the reversion. An increase in the annealing temperature to 550 and $600{ }^{\circ} \mathrm{C}$ resulted in some coarsening of the grain/subgrain size. Surprisingly, the grain size decreased after annealing at $650{ }^{\circ} \mathrm{C}$. This effect can be associated with both a large amount of reversion and recrystallizing nuclei and the pinning effect of carbides that may also inhibit the reversion and recrystallization rate and enhance the UFG/NG structure [26]. Remarkable structure 
coarsening took place after annealing at $700{ }^{\circ} \mathrm{C}$ and above (Figure 8) when $\alpha$-phase almost disappeared (Figure 5a). A decrease in dislocation density with increasing annealing temperature was also detected (Figure 8) due to the development of recovery, recrystallization, and diffusional reversion.

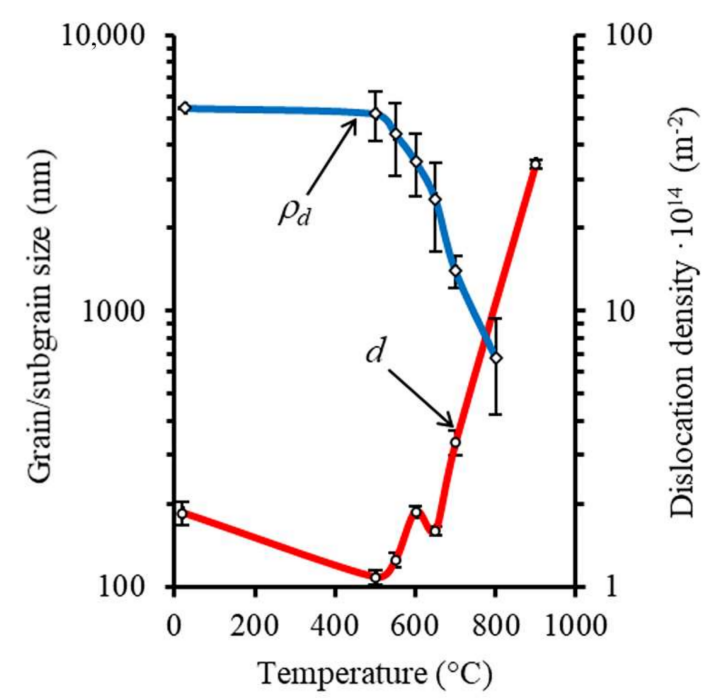

Figure 8. Effect of annealing temperature on the transversal grain/subgrain size (d) and the dislocation density $\left(\rho_{\mathrm{d}}\right)$. The error bars on the plots denoted the confidence interval with the significance level of $5 \%$.

Based on the microstructural observations above, three different temperature ranges of annealing treatment can be established: low- $\left(500-650^{\circ} \mathrm{C}\right)$, medium- $\left(700^{\circ} \mathrm{C}\right)$, and hightemperature annealing $\left(800^{\circ} \mathrm{C}\right)$. The major features of different annealing modes obtained by TEM-observations (Figures 2, 6 and 7) were presented in the scheme of the structure evolution during annealing (Figure 9). During low-temperature annealing, simultaneous development of the martensite-to-austenite reversion, recrystallization, and carbide precipitation resulted in the nucleation of new austenite grains and restriction of their growth. As a result, an ultrafine-grained structure with an average grain size of 100-200 nm was observed (Figure 8). The fine structure can be beneficial in terms of strength-ductility synergy [47]. Furthermore, such an annealing mode might be considered as a promising regime for practical applications. The martensite-to-austenite reversion occurred by both martensitic and diffusional mechanisms. Within lamellar regions, martensitic shear reversion developed via lath-to-lath mechanism (Figure 6b,c), though austenitic plates also formed within equiaxed martensitic grains (Figure 6e). Diffusional reversion was associated with the formation of dislocation-free equiaxed austenitic grains wherever (Figure $6 b, e$ ). In the current study, the heating rate during annealing was $\sim 10^{\circ} \mathrm{C} / \mathrm{s}$. It means that, according to the reversion-temperature-time diagram proposed from dilatometry analysis (Figure $4 \mathrm{~b}$ ), the onset of the reversion must happen via the martensitic mechanism. Diffusional reversion and recrystallization likely developed during subsequent heating or soaking that also resulted in slow decreasing dislocation density (Figure 8).

Medium-temperature annealing (Figure 9) produced the almost fully recrystallized austenitic structure within regions with the equiaxed deformed structure (Figure 7a). Yet, the lamellar unrecrystallized regions were still preserved (Figure $7 \mathrm{~b}$ ). Here, after complete martensite-to-austenite reversion, the reverted austenite size might correspond to the previous packet or block size (Figure $7 \mathrm{~b}$ ) that was observed elsewhere [20]. Interestingly, the gradual development of recrystallization still occurs mainly in areas with an initial equiaxed structure, while lamellar structure areas remain practically unaffected by recrystallization. This can be associated with fewer dislocations accumulated within lamellar regions resulting in the absence of transformation to the equiaxed structure. Meanwhile, the average grain size exceeded $300 \mathrm{~nm}$ and dislocation density significantly decreased 
(Figure 8). According to [48], unrecrystallized austenite areas after post deformation annealing possessed relatively low Schmid factor based on austenite slip system $\{111\}\langle 110\rangle$ that resulted in lower dislocation density and driving force for recrystallization. Because of the different driving forces, large and fine grains would be obtained via recrystallization from retained austenite and $\alpha^{\prime}$-martensite, respectively [48]. After high-temperature annealing, obtaining of the equiaxed structure was detected (Figure $7 \mathrm{c}$ ). Furthermore, the significant growth of austenitic grains higher than $1 \mu \mathrm{m}$ and the decrease in dislocation density were obtained (Figure 8).

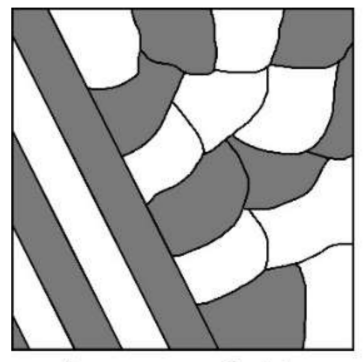

As-processed state

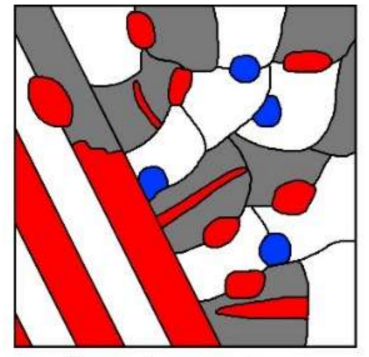

Low-temperature annealing

Color code: Retained austenite

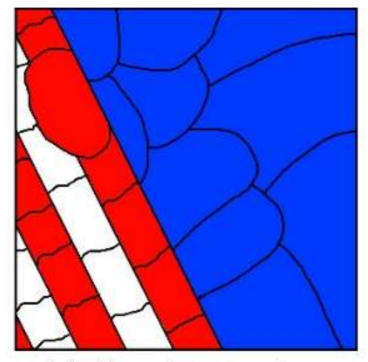

Medium-temperature annealing

Reverted austenite

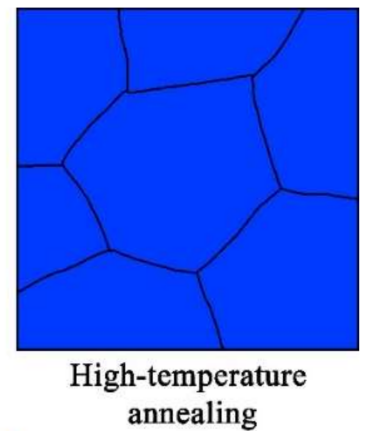

Recrystallized austenite

Figure 9. Scheme of the structure evolution during phase reversion annealing.

The received results will be useful for manufacturing stainless materials with good strength-ductility synergy. As was shown above, it is possible to receive the ultrafinegrained structure with an average grain size of 100-200 $\mathrm{nm}$ by the sequence of cold swaging with a strain of $90 \%$ and subsequent low-temperature $\left(500-650{ }^{\circ} \mathrm{C}\right)$ reverse annealing. In this way, comprehensive testing of mechanical properties of the program steel after the annealing modes might be considered as the further development of the current study.

\section{Conclusions}

The mechanisms of phase reversion and the effect of phase reversion annealing on the structure of the commercial type 321 metastable austenitic stainless steel subjected to cold swaging were studied. The following conclusions are the main results received in the current work:

1. During continuous heating, three following processes were separated using highresolution dilatometry: martensitic shear reversion-first reversion stage; diffusional reversion-second reversion stage; recrystallization.

2. The reversion-temperature-time diagram for the as-processed 321 MAS steel was constructed. The reverse transformation start temperature $\left(\mathrm{A}_{\mathrm{S}}\right)$ was $\sim 530{ }^{\circ} \mathrm{C}$ and $\operatorname{did}$ not depend on the heating rate. So, the start of the first reversion stage did not also depend on the heating rate, but the finish of the first reversion stage increased with the rising of the heating rate as well as the onset and end of the second reversion stage and the temperature range of recrystallization. The heating with a rate higher than $\sim 10^{\circ} \mathrm{C} / \mathrm{s}$ was associated with the development of both reversion mechanisms separately. Diffusional reversion developed during subsequent heating or soaking. At slow heating rates $\left(<10^{\circ} \mathrm{C} / \mathrm{s}\right)$, both mechanisms might occur simultaneously during continuous heating.

3. Reverse annealing modes could be divided into low- $\left(500-650{ }^{\circ} \mathrm{C}\right)$, medium$\left(\sim 700^{\circ} \mathrm{C}\right)$, and high-temperature reverse annealing $\left(\sim 800^{\circ} \mathrm{C}\right)$. Low-temperature annealing was associated with an ultrafine grain structure with an average grain size of 100-200 nm due to the development of the phase reversion, recovery, recrystallization, and carbide precipitation. Medium-temperature annealing was characterized by the formation of almost a fully recrystallized austenitic structure, but the lamellar regions were still detected. Austenitic grain growth and coagulation and dissolution of carbide particles were enhanced during high-temperature annealing. 
4. The phase reversion occurred by both martensitic and diffusional mechanisms. The enhancement of martensitic reversion within lamellar regions occurred via the lath-to-lath mechanism, however austenitic plates also formed within equiaxed martensitic grains. Diffusional reversion resulted in the formation of dislocation-free equiaxed austenitic grains wherever. During applied annealing with a heating rate of $\sim 10{ }^{\circ} \mathrm{C} / \mathrm{s}$, the onset of the reversion developed through the martensitic mechanism due to the separation of martensitic and diffusional reversion. Diffusional reversion developed during subsequent heating or soaking.

Supplementary Materials: The following are available online at https:/ / www.mdpi.com/article/10 $.3390 /$ met11040599/s1, Figure S1: The results of dilatometric measurements at a heating rate of $(\mathbf{a}, \mathbf{b})$ 90, (c,d) 10, (e,f) 0.6 , and (g,h) $0.15^{\circ} \mathrm{C} / \mathrm{s}$ of as-processed program steel: $(\mathbf{a}, \mathbf{c}, \mathbf{e}, \mathbf{g})$-dilatogram $(\Delta \mathbf{l})$ and the first derivative $(\mathrm{d}(\Delta \mathrm{l}) / \mathrm{dt}) ;(\mathbf{b}, \mathbf{d}, \mathbf{f})$ - set value of temperature (Set value), the real temperature of a specimen $(t)$, the difference between the set value of temperature and real temperature of a specimen $(\Delta \mathrm{t})$.

Author Contributions: D.P.—investigation, methodology, visualization, writing —original draft preparation; E.K., A.S., R.C.—investigation; Y.S., N.S., S.Z., and G.S.—validation, writing-review and editing. All authors have read and agreed to the published version of the manuscript.

Funding: This research was funded by the Russian Science Foundation Grant no. 20-79-10094.

Institutional Review Board Statement: Not applicable.

Informed Consent Statement: Not applicable.

Data Availability Statement: Not applicable.

Acknowledgments: The authors are grateful to the personnel of the Joint Research Center, "Technology and Materials", Belgorod National Research University, for their assistance.

Conflicts of Interest: The authors declare no conflict of interest.

\section{References}

1. Beddoes, J.; Parr, J.G. Introduction to Stainless Steels, 3rd ed.; ASM International, Materials Park: Russell, OH, USA, 1999.

2. Lo, K.H.; Shek, C.H.; Lai, J.K.L. Recent developments in stainless steels. Mater. Sci. Eng. R Rep. 2009, 65, 39-104. [CrossRef]

3. Hall, E.O. The deformation and aging of mild steel: III. Discussion of results. Proc. Phys. Soc. Lond. 1951, 64, 747. [CrossRef]

4. Petch, N.J. The ductile-brittle transition in the fracture of $\alpha$-iron: I. Philos. Mag. 1958, 3, 1089-1097. [CrossRef]

5. Rezaei, H.A.; Ghazani, M.S.; Eghbali, B. Effect of post deformation annealing on the microstructure and mechanical properties of cold rolled AISI 321 austenitic stainless steel. Mater. Sci. Eng. A 2018, 736, 364-374. [CrossRef]

6. Dobatkin, S.V.; Skrotzki, W.; Rybalchenko, O.V.; Terent'ev, V.F.; Belyakov, A.N.; Prosvirnin, D.V.; Raab, G.I.; Zolotarev, E.V. Structural changes in metastable austenitic steel during equal channel angular pressing and subsequent cyclic deformation. Mater. Sci. Eng. A 2018, 723, 141-147. [CrossRef]

7. Dobatkin, S.V.; Rybal'chenko, O.V.; Raab, G.I. Structure formation, phase transformations and properties in Cr-Ni austenitic steel after equal-channel angular pressing and heating. Mater. Sci. Eng. A 2007, 463, 41-45. [CrossRef]

8. He, Y.M.; Wang, Y.H.; Guo, K.; Wang, T.S. Effect of carbide precipitation on strain-hardening behavior and deformation mechanism of metastable austenitic stainless steel after repetitive cold rolling and reversion annealing. Mater. Sci. Eng. A 2017, 708, 248-253. [CrossRef]

9. Salishchev, G.A.; Zaripova, R.G.; Zakirova, A.A. Structure and properties of stainless steels subjected to severe plastic deformation. Met. Sci. Heat Treat. 2006, 48, 70-75. [CrossRef]

10. Panov, D.; Pertsev, A.; Smirnov, A.; Khotinov, V.; Simonov, Y. Metastable austenitic steel structure and mechanical properties evolution in the process of cold radial forging. Materials 2019, 12, 2058. [CrossRef]

11. De, A.K.; Speer, J.G.; Matlock, D.K.; Murdock, D.C.; Mataya, M.C.; Comstock, R.J. Deformation-induced phase transformation and strain hardening in type 304 austenitic stainless steel. Metall. Mater. Trans. A Phys. Metall. Mater. Sci. 2006, 37, 1875-1886. [CrossRef]

12. Shakhova, I.; Dudko, V.; Belyakov, A.; Tsuzaki, K.; Kaibyshev, R. Effect of large strain cold rolling and subsequent annealing on microstructure and mechanical properties of an austenitic stainless steel. Mater. Sci. Eng. A 2012, 545, 176-186. [CrossRef]

13. Brooks, J.W.; Loretto, M.H.; Smallman, R.E. Direct observations of martensite nuclei in stainless steel. Acta Metall. 1979, 27, 1839-1847. [CrossRef]

14. Shen, Y.F.; Li, X.X.; Sun, X.; Wang, Y.D.; Zuo, L. Twinning and martensite in a 304 austenitic stainless steel. Mater. Sci. Eng. A 2012, 552, 514-522. [CrossRef] 
15. Su, J.; Wu, X.; Raabe, D.; Li, Z. Deformation-driven bidirectional transformation promotes bulk nanostructure formation in a metastable interstitial high entropy alloy. Acta Mater. 2019, 167, 23-39. [CrossRef]

16. Xu, D.; Wan, X.; Yu, J.; Xu, G.; Li, G. Effect of cold deformation on microstructures and mechanical properties of austenitic stainless steel. Metals 2018, 8, 522. [CrossRef]

17. Gu, J.; Zhang, L.; Ni, S.; Song, M. Effects of grain size on the microstructures and mechanical properties of 304 austenitic steel processed by torsional deformation. Micron 2018, 105, 93-97. [CrossRef] [PubMed]

18. Shakhova, I.; Belyakov, A.; Kaibyshev, R.; Kimura, Y.; Tsuzaki, K. Submicrocrystalline structures and tensile behaviour of stainless steels subjected to large strain deformation and subsequent annealing. Adv. Mater. Res. 2012, 409, 607-612. [CrossRef]

19. Lei, C.; Deng, X.; Li, X.; Wang, Z. Simultaneous enhancement of strength and ductility through coordination deformation and multi-stage transformation induced plasticity (TRIP) effect in heterogeneous metastable austenitic steel. Scr. Mater. 2019, 162, 421-425. [CrossRef]

20. Tomimura, K.; Takaki, S.; Tokunaga, Y. Reversion Mechanism from Deformation Induced Martensite to Austenite in Metastable Austenitic Stainless Steels. ISIJ Int. 1991, 31, 1431-1437. [CrossRef]

21. Misra, R.D.K.; Zhang, Z.; Venkatasurya, P.K.C.; Somani, M.C.; Karjalainen, L.P. Martensite shear phase reversion-induced nanograined/ultrafine-grained Fe-16Cr-10Ni alloy: The effect of interstitial alloying elements and degree of austenite stability on phase reversion. Mater. Sci. Eng. A 2010, 527, 7779-7792. [CrossRef]

22. Shirazi, H.; Miyamoto, G.; Hossein Nedjad, S.; Chiba, T.; Nili Ahmadabadi, M.; Furuhara, T. Microstructure evolution during austenite reversion in Fe-Ni martensitic alloys. Acta Mater. 2018, 144, 269-280. [CrossRef]

23. Johannsen, D.L.; Kyrolainen, A.; Ferreira, P.J. Influence of annealing treatment on the formation of nano/submicron grain size AISI 301 Austenitic stainless steels. Metall. Mater. Trans. A 2006, 37, 2325-2338. [CrossRef]

24. Leem, D.S.; Lee, Y.D.; Jun, J.H.; Choi, C.S. Amount of retained austenite at room temperature after reverse transformation of martensite to austenite in an Fe-13\%Cr-7\%Ni-3\%Si martensitic stainless steel. Scr. Mater. 2001, 45, 767-772. [CrossRef]

25. Aletdinov, A.; Mironov, S.; Korznikova, G.F.; Konkova, T.; Zaripova, R.G.; Myshlyaev, M.M.; Semiatin, S.L. Martensite-toAustenite Reversion and Recrystallization in Cryogenically-Rolled Type 321 Metastable Austenitic Steel. Metall. Mater. Trans. A Phys. Metall. Mater. Sci. 2019, 50, 1346-1357. [CrossRef]

26. Tiamiyu, A.A.; Odeshi, A.G.; Szpunar, J.A. Austenitic Reversion of Cryo-rolled Ti-Stabilized Austenitic Stainless Steel: HighResolution EBSD Investigation. J. Mater. Eng. Perform. 2018, 27, 889-904. [CrossRef]

27. Sagaradze, V.V.; Danilchenko, V.E.; L'Heritier, P.; Shabashov, V.A. The structure and properties of Fe-Ni alloys with a nanocrystalline austenite formed under different conditions of $\gamma-\alpha-\gamma$ transformations. Mater. Sci. Eng. A 2002, 337, 146-159. [CrossRef]

28. Nakada, N.; Tsuchiyama, T.; Takaki, S.; Hashizume, S. Variant selection of reversed austenite in lath martensite. ISIJ Int. 2007, 47, 1527-1532. [CrossRef]

29. Zhang, X.; Miyamoto, G.; Toji, Y.; Nambu, S.; Koseki, T.; Furuhara, T. Orientation of austenite reverted from martensite in Fe-2Mn-1.5Si-0.3C alloy. Acta Mater. 2018, 144, 601-612. [CrossRef]

30. Kisko, A.; Hamada, A.S.; Talonen, J.; Porter, D.; Karjalainen, L.P. Effects of reversion and recrystallization on microstructure and mechanical properties of Nb-alloyed low-Ni high-Mn austenitic stainless steels. Mater. Sci. Eng. A 2016, 657, 359-370. [CrossRef]

31. Lee, S.J.; Park, Y.M.; Lee, Y.K. Reverse transformation mechanism of martensite to austenite in a metastable austenitic alloy. Mater Sci. Eng. A 2009, 515, 32-37. [CrossRef]

32. Son, Y.I.; Lee, Y.K.; Park, K.T. Reverse transformation of ferrite and pearlite to austenite in an ultrafine-grained low-carbon steel fabricated by severe plastic deformation. Metall. Mater. Trans. A Phys. Metall. Mater. Sci. 2006, 37, 3161-3164. [CrossRef]

33. Pawłowski, B. Determination of critical points of hypoeutectoid steels. Arch. Metall. Mater. 2012, 57, 957-962. [CrossRef]

34. Panov, D.O.; Smirnov, A.I. Features of austenite formation in low-carbon steel upon heating in the intercritical temperature range. Phys. Met. Metallogr. 2017, 118, 1081-1090. [CrossRef]

35. Sun, G.S.; Du, L.X.; Hu, J.; Misra, R.D.K. Microstructural evolution and recrystallization behavior of cold rolled austenitic stainless steel with dual phase microstructure during isothermal annealing. Mater. Sci. Eng. A 2018, 709, 254-264. [CrossRef]

36. Wojdyr, M. Fityk: A general-purpose peak fitting program. J. Appl. Crystallogr. 2010, 43, 1126-1128. [CrossRef]

37. Panov, D.O.; Smirnov, A.I.; Pertsev, A.S. Formation of Structure in Metastable Austenitic Steel during Cold Plastic Deformation by the Radial Forging Method. Phys. Met. Metallogr. 2019, 120, 184-190. [CrossRef]

38. Tiamiyu, A.A.; Odeshi, A.G.; Szpunar, J.A. Multiple strengthening sources and adiabatic shear banding during high strain-rate deformation of AISI 321 austenitic stainless steel: Effects of grain size and strain rate. Mater. Sci. Eng. A 2018, 711, 233-249. [CrossRef]

39. Lei, C.; Li, X.; Deng, X.; Wang, Z.; Wang, G. Deformation mechanism and ductile fracture behavior in high strength high ductility nano/ultrafine grained Fe-17Cr-6Ni austenitic steel. Mater. Sci. Eng. A 2018, 709, 72-81. [CrossRef]

40. Cherepin, V.T. Eksperimental'naia Tekhnika v Fizicheskom Metallovedenii; Tekhnika: Kiev, Ukraine, 1968. (In Russian)

41. He, Y.; Zhang, J.; Wang, Y.; Wang, Y.; Wang, T. The expansion behavior caused by deformation-induced martensite to austenite transformation in heavily cold-rolled metastable austenitic stainless steel. Mater. Sci. Eng. A 2019, 739, 343-347. [CrossRef]

42. Liu, G.; Li, J.; Zhang, S.; Wang, J.; Meng, Q. Dilatometric study on the recrystallization and austenization behavior of cold-rolled steel with different heating rates. J. Alloys Compd. 2016, 666, 309-316. [CrossRef]

43. Sun, G.S.; Hu, J.; Zhang, B.; Du, L.X. The significant role of heating rate on reverse transformation and coordinated straining behavior in a cold-rolled austenitic stainless steel. Mater. Sci. Eng. A 2018, 732, 350-358. [CrossRef] 
44. Weidner, A.; Hangen, U.D.; Biermann, H. Nanoindentation measurements on deformation-induced $\alpha$-martensite in a metastable austenitic high-alloy CrMnNi steel. Philos. Mag. Lett. 2014, 94, 522-530. [CrossRef]

45. Apple, C.A.; Krauss, G. The Effect of heating rate on the martensite to austenite transformation in Fe-Ni-C Alloys. Acta Met. 1972, 20, 849-856. [CrossRef]

46. Rajasekhara, S.; Karjalainen, L.P.; Kyröläinen, A.; Ferreira, P.J. Microstructure evolution in nano/submicron grained AISI 301LN stainless steel. Mater. Sci. Eng. A 2010, 527, 1986-1996. [CrossRef]

47. Di Schino, A.; Barteri, M.; Kenny, J.M. Development of ultra fine grain structure by martensitic reversion in stainless steel. J. Mater. Sci. Lett. 2002, 21, 751-753. [CrossRef]

48. Sun, G.; Du, L.; Hu, J.; Zhang, B.; Misra, R.D.K. On the influence of deformation mechanism during cold and warm rolling on annealing behavior of a 304 stainless steel. Mater. Sci. Eng. A 2019, 746, 341-355. [CrossRef] 